\title{
GESTÃO DEMOCRÁTICA DA ESCOLA E GESTÃO DO ENSINO: A CONTRIBUIÇÃO DOCENTE À CONSTRUÇÃO DA AUTONOMIA NA ESCOLA
}

\author{
Maria do Carmo Gonçalo Santos* \\ Mônica Patrícia da Silva Sales**
}

RESUMO: O paradigma da gestão democrática da escola, enquanto princípio Constitucional crítico, indo além da dimensão burocrática da administração clássica, e também, enquanto ideologia neoliberal do Estado mínimo, é problematizado neste texto para analisarmos suas perspectivas na contemporaneidade. Este trabalho, de natureza qualitativa, busca o conteúdo latente da realidade (LÜDKE; ANDRÉ, 1986) e utiliza a pesquisa bibliográfica como caminho para articular síntese e análise, a partir do estado da arte (MINAYO, 2000). Apresenta a apropriação e distorção do conceito de gestão democrática, realizado pelas políticas educacionais neoliberais (BASTOS, 1999; LÜCK, 2006; LIBÂNEO, 2003). A pesquisa focaliza a docência como um trabalho de gestão do ensino (GAUTHIER, 1999), capaz de contribuir para a construção de uma cultura democrática e de uma autonomia na escola.

Palavras-chave: Gestão democrática da escola. Trabalho docente. Liderança na escola.

\section{DEMOCRATIC SCHOOL MANAGEMENT AND EDUCATION MANAGEMENT: TEACH-} ER ASSISTANCE FOR THE CONSTRUCTION OF AUTONOMY IN SCHOOL

ABSTRACT: The paradigm of democratic management of the school, as a critical Constitutional principle, going beyond the classic bureaucratic administration, as well as the neoliberal ideology of Minimal State, is problematized in this paper to analyze their prospects nowadays. This study was qualitative, seeking the latent content of reality (LÜDKE; ANDRÉ, 1986) and uses bibliographic research as a way to articulate the synthesis and analysis from the state of the art (MINAYO, 2000). It presents the appropriation and distortion of the concept of democratic management, carried out by neo-liberal educational policies (Bastos, 1999; LÜCK, 2006; LIBÂNEO, 2003). The research focuses on teaching pratice as a teaching management work (Gauthier, 1999), able to contribute to building of a democratic culture and autonomy in school.

Keywords: Democratic Management of the school, Teaching work, Leadership in school. 


\section{INTRODUCÃ̃}

A tendência crescente, sobretudo a partir da década de oitenta, de se falar em escola democrática, lançou para a comunidade social, escolar e acadêmica o desafio de se pensar em projetos educativos alternativos, contrários à centralização de poder, geralmente, promovida pelas políticas públicas de cunho neoliberal capitalista, através do controle dos recursos para a educação, da fiscalização das propostas pedagógicas das escolas e do trabalho docente, e também pelo boicote material das condições de trabalho dos/as profissionais da educação. Nessa perspectiva, buscar a autonomia da escola por meio da partilha de ideias, com oportunidade de deliberação; através da construção de um Projeto Político Pedagógico autêntico, com personalidade própria; e também por meio de grupos colegiados, constituídos por representantes de todos os segmentos da comunidade escolar, são caminhos pensados e trilhados atualmente pelas escolas que perseguem a gestão democrática.

Neste trabalho, discutimos a construção do conceito de gestão escolar, analisando as perspectivas da gestão democrática na contemporaneidade, o que nos levou a focalizar o trabalho docente como um trabalho de gestão.

$\mathrm{Na}$ primeira parte do texto, tratamos do conceito de gestão democrática da escola em relação à mudança do paradigma de administração para o de gestão. Anunciamos que a gestão engloba e amplia a perspectiva da administração, uma vez que propõe relações mais dinâmicas, dialógicas e humanas no interior das instituições, além disso, preocupa-se mais com o processo do que com o produto, e o foco é a qualidade, não apenas a quantidade.

Destacamos, ainda, que o discurso da gestão democrática tem sido apropriado pela perspectiva dominante, cujos princípios da descentralização, da participação e da qualidade são direcionados à produtividade e instrumentalização dos sistemas de ensino, em vista de atender aos interesses do mercado de trabalho e à ideologia neoliberal, que fragiliza a função do Estado. Enfatizamos, portanto, a necessidade de se compreender a gestão democrática da escola como uma possibilidade de envolver a comunidade no processo de reflexão, desenvolvimento e avaliação de políticas públicas no interior da escola, não enquanto apropriação privada do espaço público, mas como acompanhamento e controle do serviço pela comunidade (BASTOS, 1999; GADOTTI, 1997; LIBÂNEO, 2003; ZEICHNER,).

Após essa discussão mais ampla, focalizamos o trabalho docente como um trabalho de gestão. Dizemos que o/a professor/a tem atribuições relativas ao ensino, mas que essas se estendem e se articulam ao todo da escola. Ao destacarmos as demandas contemporâneas para o trabalho docente, identificamos as dimensões técnica, político-pedagógica e epistemológicas como fundamentos para orientar o/a professor/a na construção de uma cultura democrática na escola, identificando-o como uma importante liderança para os/as alunos/ as, para a comunidade escolar e para ele/a mesmo, em vista de poder gerir a sua profissionalização (GAUTHIER, 1998; LÜCK, 2009; SAVIANI, 2000). A 
articulação ensino-pesquisa, neste trabalho, é focalizada como o sustento para ampliar o horizonte de visão e compreensão do/a professor/a sobre a educação, estimulando-o/a a pensar de forma crítica e não passiva.

Elegemos a pesquisa qualitativa para orientar metodologicamente as nossas investigações e escolhas, uma vez que buscamos não apenas o explícito, o visível e o concreto, pois “...os estudos qualitativos permitem iluminar o dinamismo interno das situações” (LÜDKE; ANDRE, 1986, p.12), já que a discussão sobre gestão democrática nos provoca a analisar as entrelinhas do conteúdo da informação, nem sempre coerentes com a realidade. Desenvolvemos uma pesquisa bibliográfica, compreendendo-a como possibilitadora de articulações, diálogos e aproximações da literatura já produzida, no intuito de fazer nossas sínteses e atribuir o nosso significado, contribuindo com um olhar diferente, a partir do nosso foco de análise (SANTOS, 1999).

O estudo dos textos foi realizado a partir da construção de esquemas que nos ajudaram no momento da leitura flutuante dos dados (BARDIN, 1977), pois encontramos neles as aproximações e distanciamentos que precisavam ser considerados, já que na pesquisa qualitativa nada pode ser desperdiçado.

Ao analisarmos o conceito de gestão democrática da escola, atentando para seus princípios e tendências, chegamos ao trabalho docente como uma das dimensões da gestão no interior da escola, capaz de contribuir diretamente para a construção de uma cultura democrática na escola e para um processo de reflexão, individual e coletivo, no qual o/a próprio/a professor/a passa a autogerir e gestar a sua profissionalização. Essas considerações caminham no sentido contrário à transferência de responsabilidades para a escola e para o/a professor/a, projeto arquitetado pela política dominante, em busca de uma provocação ao controle e à intervenção da comunidade escolar nas políticas públicas, não simplesmente para executá-las, mas para analisar, intervir, cobrar e elaborar propostas mais contextualizadas e qualitativas para a escola.

\section{GESTÃO DEMOCRÁTICA DA ESCOLA: BASES POLÍTICAS, PEDAGÓGICAS E EPISTEMOLÓGICAS}

A partir da compreensão de gestão, como processo político-filosófico e administrativo de condução de um empreendimento humano-institucional, supera-se a dimensão técnico-burocrática do paradigma da administração clássica, incorporado, inclusive, pelas escolas, sobretudo no período do regime militar. O conceito de administração passou a ser questionado devido às indagações feitas à própria teoria da administração, por conta da insuficiência explicativa do processo administrativo, que, inclusive, revela a fragilidade de fatores que dão sustentação a essa teoria, como o fundamento da autoridade central, da hierarquização das relações, da fragmentação do processo produtivo, da preocupação excessiva com o produto, em detrimento do processo (DIAS, 2004). 
Com a superação do paradigma da administração clássica, a gestão passa a ser um conceito global e uma proposta ampla que colocam em questão a centralização/descentralização de poder no interior de uma empresa, instituição ou organização. O paradigma da gestão engloba o próprio conceito de administração (atividade de planejamento, execução e avaliação), de cogestão (participação coletiva) e de autogestão (ausência de diretividade), que além de ultrapassar a dimensão exclusivamente administrativa institucional, que enfoca a ação, a produção e a técnica, propondo um repensar de princípios humanos que estão presentes nas instituições, empresas e organizações, sobretudo ressignifica a compreensão de liderança dos empreendimentos. Nesse sentido, a figura do/da líder tende a ser enfraquecida, já que o poder emerge da coletividade, pois como empreendimento humano-social, a instituição, empresa ou organização não necessitará mais da relação de mando, já que nessa proposta cada sujeito tem consciência da "missão"1 institucional e da sua contribuição à coletividade. Assim, os estilos de liderança autocrática (centralização de poder) vão sendo superados pela democrática (poder partilhado) e, numa dimensão mais utópica e pouco utilizada na nossa realidade, o estilo laissez-faire (ausência de poder) (id.).

No nosso contexto neoliberal capitalista, a discussão da gestão merece cuidados, pois sua essência tende a ser distorcida, ou seja, a ideia da gestão democrática passa, muitas vezes, a ser utilizada como mote à convocação e sensibilização dos sujeitos para o engajamento na realização de tarefas que se distanciam do objetivo central da gestão democrática, a descentralização de poder, haja vista que na divisão social do trabalho, a relação é de polarização entre os que planejam e os que executam. Assim, os sujeitos se sentem envolvidos por uma pseudo-democratização, a fim de alcançar a qualidade total, passam a ser chamados e se reconhecem como colaboradores, parceiros, voluntários ou sócios. A cautela na compreensão e na utilização do termo "gestão democrática" precisa estar presente não só no ambiente empresarial, mas também, e sobretudo, nas escolas, por serem instituições com finalidade educativa, mesmo na rede particular de ensino.

A discussão sobre a gestão democrática da escola na contemporaneidade faz parte de aspirações de grupos com perspectivas político-pedagógicas distintas, ou seja, voltadas para o envolvimento da sociedade nas propostas e decisões da escola e voltadas para a desobrigação do Estado com a educação pública.

A primeira perspectiva assume um caráter crítico-progressista, no qual a gestão democrática tem como princípios a participação de toda a comunidade escolar na construção e no desenvolvimento do Projeto Político Pedagógico, da autonomia, inclusive financeira, da escola e da descentralização de poder e de tarefas relativas à organização e ao funcionamento da escola, cujo objetivo principal é a qualidade da educação, tendo em vista que para funcionar com qualidade, é preciso que haja a participação da comunidade (PARO, 2003).

De acordo com a segunda perspectiva, de caráter neoliberal, na qual o mercado passa a ser o regulador das relações sociais e político-econômicas e a escola assume a tarefa de preparar recursos humanos para a nova organização do 
trabalho que se instala, a gestão democrática é revestida do discurso da descentralização, em que o que ocorre é a desresponsabilização do Estado com a educação pública; inclusive, permanecendo a centralização do poder nas decisões relativas à educação, tendo em vista o controle do MEC sobre as Secretarias de Educação (BASTOS, 2002). Podemos dizer que no nível da discussão e da efetivação a gestão democrática da escola pode significar participação quando há o envolvimento das várias instâncias da escola na discussão, no planejamento e nas decisões relativas à instituição, ou apenas significar representação, quando há órgãos colegiados na escola sem efetivo envolvimento ou poder de intervenção e decisão. Nesse último caso, citamos o exemplo de conselhos escolares cujo presidente é o gestor ou gestora da escola e este inibe ou cerceia a participação dos outros membros, impondo suas decisões. Outro exemplo é a presença do grêmio escolar na escola sem apoio da gestão, ou, ainda, manipulado por ela. Mais um exemplo é a existência do P.P.P. na escola, construído sem a participação da comunidade escolar, ou, ainda, sem ter suas propostas concretizadas e sem ser atualizado.

Segundo Gadotti (1994), os riscos apontados pelos críticos da autonomia escolar e da gestão dizem respeito à privatização e, ainda, ao localismo que dispersa os interesses coletivos, voltando-se apenas à preocupação individualizada e isolada em cada escola. Esse mesmo autor (id.) nos ajuda a compreender que autonomia articula-se ao pluralismo, hoje defendido como valor universal, pois

\footnotetext{
A autonomia se refere à criação de novas relações sociais que se opõem às relações autoritárias existentes. Autonomia é o oposto de uniformização. A autonomia admite a diferença e, por isso, supõe a parceria. Só a igualdade na diferença e a parceria são capazes de criar o novo. Por isso, escola autônoma não significa escola isolada, mas em constante intercâmbio com a sociedade. (id., p.5)
}

Nesse sentido, a autonomia passa a ser conquistada a partir da criatividade e da competência em buscar novos caminhos e por meio da articulação com a comunidade, indo para além do instituído.

Segundo Bastos (2002), o debate sobre a gestão democrática da escola tem sido alimentado pela classe popular e pelos intelectuais, em uma dimensão chamada civil democrática, enquanto a proposta denominada produtivista é difundida pelos grupos empresariais e centros de decisão dos governos.

No contexto neoliberal, o dever das políticas públicas com a educação é "partilhado" com a sociedade civil, através de programas emergenciais e parcerias que não contribuem de forma estrutural com a qualidade da educação, e ainda, consolidam a prática da privatização, como se a solução para os problemas de ordem pública pudessem e devessem ser resolvidos pela iniciativa privada.

A Lei 9.394/96 que dispõe sobre as Diretrizes e Bases da Educação Nacional, sobretudo no seu artigo $3^{\circ}$, que define os princípios e fins da educação nacional, especificamente o inciso VIII, que trata do princípio da gestão democrática, e no seu artigo 14, que trata das normas de gestão democrática para a escola, expressa o seu viés neoliberal. Principalmente no que se refere à dicotomia entre 
o público e o privado, a Lei assegura o princípio da gestão democrática apenas ao ensino público, deixando clara a distinção entre ambos, inclusive, para os princípios que os norteiam. Além disso, ao deixar a cargo dos sistemas de ensino o estabelecimento das suas normas de gestão, a Lei torna-se flexível. Com relação aos conselhos escolares, a flexibilidade é ainda maior por não estabelecer seu critério deliberativo. Nesse sentido, a Lei 9.394/96 traz o princípio da gestão democrática, ratificando o artigo 206, Inciso VI, da Constituição Federal de 1988. Porém, ela não assegura a sua universalização em todos os sistemas de ensino e, ainda, não especifica os caminhos para a efetivação desse princípio (PARO, 1997)

Além desse contexto macro da política educacional, a escola ainda enfrenta os desafios micro de seu cotidiano para pensar e efetivar uma proposta progressista de gestão democrática, tendo em vista a presença da cultura do paternalismo e do clientelismo em nossa sociedade. Nessa perspectiva, a figura do gestor e da gestora confundem-se com a do provedor ou provedora, e construir uma outra concepção de gestão e outro perfil de gestor e de gestora que tomem a participação e a autonomia como praxis, demanda exercício coletivo, assim como a ruptura com o modelo hierárquico de funções e relações pedagógicas também exigem esforços partilhados.

Nesse sentido, a eleição para dirigentes escolares, prática iniciada na década de setenta, passa a ser apenas uma das ações do processo de democratização da escola, tão importante quanto o repensar das relações em seu interior.

Os movimentos sociais, principalmente os que focalizam a educação escolar em suas propostas políticas, contribuem com experiências de práticas pedagógicas compartilhadas, revelando vivências alternativas distintas da escola tradicional que, muitas vezes, incorporam modelos sistêmicos de administração e relações. Segundo LIBÂNEO; OLIVEIRA; TOSCHI (2003), os princípios e métodos da organização escolar são originários da administração mais ampla, entretanto, têm características e objetivos distintos das empresas, uma vez que seu trabalho é de natureza interativa e pedagógica. Além disso, a preocupação é com a qualidade do processo, não com os resultados quantitativos.

A gestão democrática da escola, em uma perspectiva progressista, no seu objetivo precípuo com a qualidade da educação, assume responsabilidade social de formar para a cidadania, portanto, o incentivo à participação, à circulação de informações e à viabilização de recursos para a formação e manutenção dos conselhos escolares, dos grêmios estudantis e das associações de pais e mestres são ações que demandam esforço, sobretudo, da equipe técnico-pedagógica da escola e dos seus professores, para o cumprimento dessa proposta política que ultrapassa os muros da escola e vai além do instituído.

Para nós o/a professor/a, assim como o/a gestor/a da escola, são figuras-chave do projeto de escola democrática e de democratização da educação, uma vez que no seio da instituição escolar, são os principais fomentadores das políticas educacionais, entendendo que estas não se dão só na esfera macro, mas acontecem no cotidiano da sala de aula e da escola, através de concepções, práticas, propostas e exemplos concretos. 


\section{GESTÃO ESCOLAR E GESTÃO DO ENSINO: A EDUCAÇÃO PARA A DEMOCRATIZAC̣ÃO}

Ao discutirmos sobre a mudança de paradigmas de administração para gestão, compreendendo que a ação de administrar está contida na de gerir, esta sendo muito mais ampla, coletiva e processual, percebemos que o trabalho docente se situa na interface entre a gestão educacional (dos sistemas de ensino), gestão escolar (das escolas) e do ensino (trabalho docente).

A partir da compreensão de que a escola faz parte de um contexto social dinâmico e complexo, que é movida também por políticas sociais macro, e que as relações vivenciadas no seu interior envolvem sujeitos multiprofissionais (SORATTO, 1999), focalizamos o/a professor/a como um dos/as mediadores/as do processo de mudança de concepções e de criação de uma cultura democrática na escola; uma vez que ele/a atua diretamente com os/as alunos/as, sujeitos da educação sistematizada.

O trabalho docente, enquanto atividade-fim da escola, que tem como objetivo principal a aprendizagem dos/as alunos/as (id.), ocorre por meio dos processos de gestão da matéria (referentes ao planejamento, ao ensino e à avaliação da aula) e de gestão da sala de aula (referentes ao conjunto de regras e de mecanismos para criar e manter o ambiente favorável à aprendizagem) (GAUTHIER, 1998), mas não se circunscreve aos limites da sala de aula e às relações

com os/as alunos/as, uma vez que se insere em uma teia mais ampla de relações e objetivos que ultrapassam esses domínios.

A partir da Lei 9.394/96, Lei de Diretrizes e Bases da Educação Nacional, Artigo 13, os docentes têm incumbências relativas à participação na elaboração da proposta pedagógica da escola, à elaboração e cumprimento do plano de trabalho, ao acompanhamento das aprendizagens e promoção de estratégias de recuperação dos/as alunos/as, à vivência dos dias letivos e dos períodos de planejamento, avaliação e formação; além de contribuir com a articulação família-escola. Diante dessas atribuições definidas por Lei, destacamos a importância do conteúdo dos incisos I e VI, que tratam, respectivamente, da participação docente na elaboração do P.P.P. e na articulação entre escola e família, uma vez que essas ações contribuem para a compreensão da função docente como uma função social mais ampla. Assim, os/as professores/as podem mediar o trabalho da escola com as famílias, ajudando a construir uma cultura mais democrática na escola.

Podemos fazer uma analogia entre o trabalho docente e o trabalho da gestão escolar devido às dimensões articuladas, envolvidas em ambas as funções, e devido ao sentido de liderança que estes sujeitos, professores/as e gestores/as, assumem nas suas atuações.

Em relação às dimensões, situamos a dimensão político-pedagógica como aquela que direciona, que orienta a intencionalidade do trabalho docente e da gestão. Ela é a dimensão técnica na qual o sujeito acumula suas experiências práticas para lidar com os desafios cotidianos da escola e da sala de aula. Articulada às anteriores, a dimensão epistemológica, que fundamenta o trabalho, a partir de 
conceitos e contribuições que ajudam a analisar, alimentar e recriar as práticas docentes e da gestão escolar.

Em relação ao sentido de liderança, situamos a necessidade da presença do/a líder como mediador/a do processo de gestão, seja da escola ou do ensino. Este/a líder-professor/a, líder-gestor/a atua com autoridade e autonomia junto à comunidade escolar, a partir de uma relação dinâmica e horizontal, entre todas as representações da instituição; circulando e atuando em todos os espaços da escola, em vista da natureza educativa do seu trabalho. O que queremos dizer é que o/a gestor/a democrático/a se contrapõe ao/à "gestor/a de gabinete", àquele/a que fica exclusivamente delegando, despachando e definindo atribuições entre quatro paredes. O/a professor/a progressista também ultrapassa o âmbito da sala de aula e do conteúdo da matéria, envolvendo-se com a dinâmica da escola e também com os saberes menos sistematizados.

Mesmo com um perfil democrático e progressista que referenda a proposta da gestão escolar e da gestão do ensino, neste texto, não defendemos a ausência de regras, de normas e de um ritual escolar, mas acreditamos que eles devem ser construídos pela própria comunidade, que sejam instituídos por ela, a partir das necessidades próprias, em articulação com a gestão dos sistemas de ensino, tendo em vista a finalidade pedagógica. A compreensão de relações mais democráticas, seja no âmbito escolar ou mais amplamente, na sociedade, muitas vezes é confundida com a ausência de liderança, de respeito nas relações, de normas, de regras e de organização do tempo e do espaço. A nossa cultura ainda colonialista nos deixou uma herança que pode ser repensada, a do autoritarismo, das relações hierárquicas e da submissão. No entanto, pensar em democracia não é ir para o pólo oposto, fazendo apologia à falta de organização, de direcionamento, de planejamento. Segundo Lück,

Merece comentário o fato de que, em nome de uma ação democrática e autônoma, muitos membros de unidades sociais, porém revelando um entendimento inadequado da questão, apresentam ressentimento e resistência contra toda e qualquer norma que possa estabelecer ordem e direcionamento ao trabalho conjunto e à qual devam atender (2006, p.45).

A gestão democrática, antiautoritária, não refuta a autoridade, mas defende que ela deve ser conquistada a partir do conhecimento, da competência, da flexibilidade, da ética dos/as mediadores/as do trabalho escolar, seja o/a gestor/a, seja o/a professor/a. Ela não é imposta pelo cargo que ocupa. A presença das lideranças na escola, através do/a gestor/a e do/a professor/a, contribui, inclusive, para estimular a construção da autonomia dos/as alunos/as e o espírito de liderança entre eles/as, uma vez que os/as alunos/as também aprendem pelo exemplo, às vezes mais do que pelo discurso.

A cultura democrática na escola define a flexibilidade nas relações no interior da instituição, a autonomia dos sujeitos nos processos de elaboração-desenvolvimento e avaliação das propostas da escola, não a inexistência de parâmetros e objetivos que norteiam o trabalho. Em entrevista à Revista Escola, Lück (2009, 
p.21) defende a necessidade da liderança e revela a diferença entre a escola onde há liderança e a escola onde não há:

Onde não existe liderança, o ritmo de trabalho é frouxo e não há a mobilização para alcançar objetivos de aprendizagem e sociais satisfatórios. As decisões são orientadas basicamente pelo corporativismo e por interesses pessoais. Geralmente, são instituições cujos estudantes apresentam baixo desempenho. Além dessas características, há outras menos visíveis, mas que têm grande impacto. Uma estrutura de gestão debilitada contribui para a formação de pessoas indiferentes em relação à sociedade.

Compreendemos que o trabalho de gestão escolar é um trabalho educativo e que demanda o conhecimento da docência, uma vez que para atuar em um âmbito mais complexo e amplo como a gestão da escola, o/a gestor/a precisa compreender de fato a dinâmica da sala de aula, que é o espaço principal da escola, no qual ocorrem as atividades-fins e, também, deve saber o que é ser professor/a, ter uma identidade construída na docência. A compreensão de que o "ser gestor/a" exige o "ser professor/a" apoia-se, inclusive, no Decreto no 27.928/2005, que regulamenta o processo para provimento de diretor das Escolas Públicas Estaduais de Pernambuco, quando dispõe no seu Art. $6^{\circ}$, Inciso II, a exigência de cinco anos de experiência no ensino público como critério para participar do processo seletivo/eletivo para gestor/a escolar. Em relação ao papel educativo do trabalho da gestão, SAVIANI (2000, p.208) diz que

Ao diretor cabe, então, o papel de garantir o cumprimento da função educativa que é a razão de ser da escola. Nesse sentido, é preciso dizer que o diretor de escola é antes de tudo, um educador; antes de ser um administrador ele é um educador. Mais do que isso: em termos típico-ideais, ele deveria ser o educador por excelência dado que, no âmbito da unidade escolar, lhe compete a responsabilidade máxima em relação à preservação do caráter educativo da instituição escolar. Esta é, em verdade, a condição precípua para que ele administre a escola mediante formas (atividades-meios) saturadas de conteúdo (atividades-fins).

A escola na contemporaneidade dificilmente conseguirá dar conta dessa responsabilidade educativa se não estiver norteada por princípios e práticas democráticas, tendo em vista que a sociedade, hoje, afirma e defende suas idiossincrasias, culturas e identidades, exigindo o direito à pluralidade cultural em relação à etnia, a gênero, à geração, à região.

Gestão e ensino fazem parte de um processo dialógico na escola, pois de acordo com uma perspectiva democrática de educação, gerir é ensinar e ensinar é gerir.

Até o momento pontuamos os objetivos do trabalho docente, das suas atribuições legais, das dimensões e do perfil de liderança para o/a professor/a progressista/a. Além disso, enfatizaremos as demandas socioprofissionais contemporâneas para essa função, tendo em vista as especificidades de cada contexto histórico-cultural.

O nosso contexto educacional, também orientado por políticas públicas neoliberais, promotoras da flexibilidade e da instabilidade profissional, da instru- 
mentalização do conhecimento, de relações menos humanas e mais produtivas, promove, na contracorrente, um movimento desafiador que instiga a formação de valores éticos, de um ensino mais problematizador e de um envolvimento maior entre escola e comunidade. A necessidade de o/a professor/a assumir a liderança da sala de aula, do seu trabalho, e da sua carreira confere um sentido de autonomia e autogoverno que se contrapõe à perspectiva dominante de gestão, viabilizada pelas políticas públicas, como afirma ZEICHNER (2002, p.28):

... a abordagem dominante tem sido preparar os professores para serem implementadores eficientes das políticas desenvolvidas por quem está fora da realidade de sala de aula. Em muitos projetos de reforma educacional ao redor do mundo, o objetivo tem sido dispor de professores que sejam servidores públicos não-reflexivos e obedientes, que fielmente implementem um currículo prescrito pelos governos usando métodos de ensino prescritos.

Em uma perspectiva crítica de gestão do ensino, novas atitudes docentes são requeridas, como a mediação da relação ativa do/a aluno/a pelo/a professor/a; a interdisciplinaridade no ensino; a promoção da metacognição dos/as alunos/as e do/a próprio professor/a; a problematização do conhecimento construído na escola; o desenvolvimento do processo comunicacional para qualificar o ensino; o diálogo com as tecnologias da informação e comunicação, as TICs; o respeito e o atendimento às diferenças socioculturais, étnicas, de gênero; o investimento na autoformação profissional contínua; a articulação entre as dimensões cognitiva e afetiva no processo de aprendizagem dos/as alunos/as e o desenvolvimento de valores éticos no ambiente escolar (LIBÂNEO, 1998).

Essas e outras atitudes merecem destaque pela possibilidade do/a professor/a contribuir com a formação de sujeitos mais críticos, mais autônomos, mais cooperativos, aproximando o trabalho docente do objetivo da escola democrática. Além disso, por compreendermos que o/a professor/a pode realizar um trabalho mais contextualizado, mais instigante para o/a aluno/a e para ele/a mesmo/a, a partir do momento em que se perceber como gestor/a também da sua profissionalização.

A partir da articulação entre gestão democrática da escola e gestão do ensino, provocamos a discussão sobre a participação da comunidade e destacamos a contribuição dos/as professores/as nos processos de gestão, pelos vários fatores enfocados acima. Não queremos, com isso, supervalorizar o trabalho docente na escola, alijando do processo os/as outros/as atores/as, como tem sido tratado pelas políticas (FREITAS, 2009) que têm dado maior atenção a esse pólo da relação, investindo em formação continuada como a solução para os problemas educacionais, dando continuidade à real desvalorização profissional e aos baixos índices de aprendizagem. Para Freitas (id., p.31)

Parte desta situação deve-se ao superdimensionamento do papel e do poder do professor, o qual tornando-se (sic) "reflexivo" poderia melhorar suas práticas e com isso ensinar melhor. Ora não só existem outros fatores impeditivos para o aumento da qualidade da escola, como há vida inteligente para além do professor ou da professora. A escola é habitada 
por diferentes profissionais e diferentes protagonistas (funcionários, estudantes, gestores, pais, etc.), sem o concurso do conjunto da escola, este sim, tendo que ser necessariamente reflexivo, limita-se em muito a possibilidade de transformação dos processos escolares.

Destacamos, portanto, a importância do princípio e da atitude na reflexão presente em todos os sujeitos da escola, inclusive, na prática docente. A reflexividade docente e escolar como um todo diz respeito à não passividade da escola em relação às políticas externas e, articulada a todo o sistema, à criação de uma política própria, pensada pelo coletivo e planejada a partir do Projeto Político Pedagógico da escola. Neste projeto, enfocamos a pesquisa como um dos caminhos possíveis para um repensar de práticas pedagógicas e docentes.

\section{CONSIDERACְ̃̃ES FINAIS}

O conceito de gestão democrática, em evidência tanto nos discursos políticos quanto na vivência concreta nos processos de formação docente e nas práticas escolares, merece ser analisado, tendo em vista sua possível banalização e uso distorcido, sobretudo a partir de uma ótica neoliberal que ao invés de contribuir para a autonomia, para a qualidade e inclusão na educação, ajuda a reforçar a centralização, a quantidade e a exclusão.

O objetivo de discutir a construção do conceito de gestão escolar, analisando as perspectivas da gestão democrática na contemporaneidade, nos levou a focalizar o trabalho docente como um trabalho de gestão.

Vimos, portanto, que a mudança do paradigma de administração para o de gestão, como um processo mais dinâmico, democrático e articulado, não exime a necessidade de ações administrativas, de planejamento, desenvolvimento e avaliação do trabalho da escola; no entanto, a gestão democrática precisa promover a sinergia pedagógica na instituição (LÜCK, 2006), como a compreensão global dos sistemas de ensino e das escolas e o esforço articulado de todos/as os/as sujeitos da educação, em vista da aprendizagem e da formação de valores humanos. Essa proposta contrapõe-se à ideia de transferência de responsabilidades para a comunidade, como uma forma de minimização do papel do Estado, própria da ideologia neoliberal, tendo em vista que a cultura da participação, fomentada a partir da escola, também ajuda a fortalecer o controle da sociedade sobre a atuação do Estado.

$\mathrm{Na}$ segunda parte deste artigo, focalizamos o trabalho docente como uma atividade também de gestão, buscando alargar a função do/a professor/a, tendo em vista sua prática social mais ampla, para além do trabalho com o ensino dos conteúdos. Assim, situamos o seu papel político, frente à formação de sujeitos mais críticos, por meio do diálogo mais próximo com a comunidade e através de um ensino mais problematizador e inquietante.

O trabalho enfatiza a importância das lideranças, a partir do/a gestor/a e do/a professor/a, na condução do trabalho da escola, na condução de processos educativos e de relações mais democráticas, uma vez que esses/as sujeitos têm, ou 
deveriam ter, um projeto social para a comunidade e a partir dela, pois

Ser docente na perspectiva da pedagogia da humanização é ser e ter preocupação com o sujeito individual e social. É ser profissional em processo de formação permanente, que a partir dessa formação inicial, do chão social da educação e com a profissão de professor/a professora, poderá contribuir para uma vida melhor através do trabalho em educação e para a construção de uma escola digna. (SANTIAGO, 2006, p.117)

A ênfase que damos ao trabalho educativo da gestão e da docência não pode ser confundida com a responsabilização única da democratização da educação para os/as educadores/as aqui focalizados/as, tendo em vista que consideramos, sobretudo, a necessidade de políticas públicas de caráter social, não só na área da educação, que possam diminuir as desigualdades. Queremos evidenciar a responsabilidade socioprofissional dos/as professores/as e gestores/as e ratificar as nossas potencialidade e competências, enquanto profissionais comprometidos/ as, abertos/as e sensíveis à melhoria da educação.

\section{NOTA}

${ }^{1}$ Missão aqui é entendida como proposta político-filosófica, e não, religiosa.

\section{REFERÊNCIAS BIBLIOGRÁFICAS}

BARDIN, Laurence. Análise de Conteúdo. Tradução de Luis Antero Reto e Augusto Pinheiro. Lisboa, Portugal: Edições 70, 2002

BASTOS, João Batista (org.). Gestão democrática. Rio de Janeiro: SEPE, 1999.

BRASIL. Congresso Nacional. Lei n. 9.394 de 20 de dezembro de 1996. Estabelece as diretrizes e bases da educação nacional. Diário Oficial da União [da] República Federativa do Brasil, Poder Executivo, Brasília, DF, 20 de dezembro de 1996.

DIAS, José Augusto. Gestão Democrática da Escola. In: MENESES, João Gualberto de. et al. Educação Básica: políticas, legislação e gestão: leituras. São Paulo: Pioneira, 2004.

FREITAS, Luiz Carlos de. et al. Avaliação educacional: caminhando pela contramão. 2. Ed. Petrópolis, RJ: Vozes, 2009. (Coleção Fronteiras Educacionais).

GADOTTI, Moacir.Gestão Democrática e Qualidade de Ensino. FÓRUM NACIONAL DESAFIO DA QUALIDADE TOTAL NO ENSINO PÚBLICO, 1. 28 a 30 de julho de 1997. Belo Horizonte- MG. Disponível em: <http://www.paulofreire.org/pub/Institu/SubInstitucional1203023491It003Ps002/Gest_democ.pdf.> Acesso em: 30 ago. 2010.

GAUTHIER, Clermont. et al. Por uma teoria da Pedagogia: pesquisas contemporâneas sobre o saber docente. Trad. Francisco Pereira. Ijuí: UNIJUÍ, 1998.

LIBÂNEO, José Carlos. Adeus professor, adeus professora? Novas exigências educacionais e profissão docente. São Paulo: Cortez, 1998. (Coleção Questões da Nossa Época; v.67).

; OLIVEIRA, João Ferreira de; TOSCHI, Mirza Seabra. Educação escolar: políticas, estrutura e organização. São Paulo: Cortez, 2003. (Coleção Docência em Formação).

LÜDKE, Menga. ; ANDRÉ, Marli E.D.A. Pesquisa em educação: abordagens qualitativas. São Paulo: EPU, 1986. 
LÜCK, Heloísa. Gestão educacional: uma questão paradigmática. Petrópolis: Vozes, 2006. (Cadernos de Gestão). . Toda a força para o líder. Nova Escola. Gestão Escolar. Editora Abril. Ano I. Nº1. Abri/maio. 2009.

MINAYO, Maria Cecília. O desafio do conhecimento: pesquisa qualitativa em saúde. 7. ed. São Paulo: Hucitec; Rio de Janeiro: Abrasco, 2000.

PARO, Vitor Henrique. Gestão democrática e a escola pública. São Paulo: Ática, 1997.

Administração escolar e qualidade do ensino: o que os pais ou responsáveis têm a ver comisso? In: LIBÂNEO, José Carlos; OLIVEIRA, João Ferreira de; TOSCHI, Mirza Seabra. Educação escolar: politicas, estrutura e organização. São Paulo: Cortez, 2003. (Coleção Docência em Formação). SANTIAGO, Eliete. Perfil do educador/educadora para a atualidade. In: NETO, José Batista; SANTIAGO, Eliete (Orgs.) Formação de professores e prática pedagógica. Recife: Fundação Joaquim Nabuco, Ed. Massagana, 2006.

SANTOS, Antônio Raimundo dos. Metodologia científica: a construção do conhecimento. Rio de Janeiro: DP\&A editora, 1999.

SORATTO, L.; OLIVIER-HECKLER, C. Escola: uma organização multiprofissional. In. CODO, Wanderley (cord.). Educação: carinho e trabalho. Petrópolis, RJ: Vozes, 1999.

SAVIANI, Dermeval. Educação: do senso comum à consciência filosófica. 13. Ed. Campinas, SP: Autores Associados, 2000. (Coleção educação contemporânea).

ZEICHNER, Kenneth. Formando professores reflexivos para uma educação centrada no aprendiz: possibilidades e contradições. In: ESTEBAN, Teresa; ZACCUR. Professora-pesquisadora: uma práxis em construção. Rio de Janeiro: DP\&A, 2002.

Data de Recebimento: 28/09/2010

Data de Aprovação: 27/04/2011

Data da Versão Final: 08/02/2012 